\title{
Impact on Drug Safety of Variation in Adherence: The Need for Routinely Reporting Measures of Dose Intensity in Medication Safety Studies Using Electronic Health Data
}

\author{
Elizabeth E. Roughead $^{1} \cdot$ Nicole L. Pratt $^{1}$
}

Published online: 18 September 2015

(C) The Author(s) 2015. This article is published with open access at Springerlink.com

\begin{abstract}
Randomized controlled trials always report the dose assessed and usually include a measure of adherence. By comparison, observational studies assessing medication safety often fail to report the dose used and rarely report any measure of adherence to therapy. This limits the ability to control for differences in doses used when undertaking meta-analyses. Non-adherence with therapy is common in the practice setting and varies across countries and settings. Inter-country differences in the registration of medicines may also result in different product strengths being available in different countries. These two factors combined means that observational studies undertaken for the same medicine in different settings may be assessing the same medicine but in circumstances where quite different dosages are used. Given that many adverse drug effects are dose dependent, differences in dosages used could be a factor explaining differences in risk estimates observed across studies. We argue that dose intensity, which can be defined as a product of the dose prescribed and adherence to the dose prescribed over the course of treatment, should be routinely reported in observational studies of medication safety. We illustrate the issue with the example of dabigatran. The randomized controlled trial evidence underpinning dabigatran's marketing authorization resulted in uncertainty about the appropriate dose for efficacy versus
\end{abstract}

Elizabeth E. Roughead

libby.roughead@unisa.edu.au

1 Quality Use of Medicines and Pharmacy Research Centre, Sansom Institute for Health Research, University of South Australia, GPO Box 2471, Adelaide, SA 5001, Australia safety. As a result, different dosages of dabigatran were registered in the USA and Europe. The USA registered the $150-$ and $75-\mathrm{mg}$ dabigatran products, while the 150 and 110-mg dabigatran products were registered in Europe. Among five observational studies subsequently undertaken to resolve the safety question concerning dabigatran and risk of bleeding, only one stratified results by dose. None of the US studies stratified results by the 75-mg dabigatran dose, despite this dose not being assessed in the original trial. None of the five studies reported adherence measures, despite three separate observational studies finding between 25 and $40 \%$ of patients were non-adherent to dabigatran. The STROBE and RECORD statements should consider adding the requirement for reporting measures of dose intensity and its component products to improve observational study reports.

\section{Key Points}

Medication dose intensity, which provides a measure of the dose given, is a function of the dose prescribed and adherence to dose prescribed within a given period of time.

A difference in dose intensity is one factor that can contribute to differences in risk estimates of medication safety across studies.

Medication dose intensity, including its component parts, should be routinely reported in observational studies assessing medication safety.

Adjusting for dose intensity will enable valid comparisons of risk estimates across studies. 


\section{Introduction}

\subsection{Reporting Medication Doses and Adherence Measures in Clinical and Observational Studies}

Randomized controlled trials assessing the safety and efficacy of new medicines always report the doses studied and generally include a measure of patient adherence with therapy during the study period. The adherence measure can be considered a process measure for the trial that enables assessment of the extent to which the intended dosage was administered. Knowledge of the extent of adherence by participants in the trial is needed to minimize the risk of bias that can arise when adherence rates differ significantly between patients in the different arms of the trial.

Similarly to randomized controlled trials, observational studies may also be subject to bias due to non-adherence with therapy. This is recognized in guidelines for reporting observational studies, including the US FDA guideline, 'Best Practices for Conducting and Reporting Pharmacoepidemiologic Studies using Electronic Health Care Data' [1]. This guideline highlights the importance of identifying gaps in therapy and determining when gaps are long enough to be a true interruption to therapy. The guideline also highlights the need to correctly ascertain dose from electronic healthcare data, and indicates the need to clearly define how this is achieved. The 'Strengthening reporting of observational studies in epidemiology' (STROBE) statement [2] also highlights the need to clearly define exposure ascertainment. The FDA guideline and STROBE statement do not include any statement about the need for reporting the doses used or adherence to the medicines. Research undertaken to develop the 'Reporting of studies conducted using observational routinely-collected data' (RECORD) statement also does not highlight the issue of reporting the dose used or adherence to the medicine under study [3]. One of the limitations of not reporting the dose used or adherence to the medicines is the lack of ability to control for drug dose in subsequent metaanalyses and systematic reviews [4].

\subsection{Dose Intensity as a Measure for Reporting Dose and Adherence}

Dose intensity is a measure commonly used in oncology to enable comparisons of chemotherapy regimens [5]. Dose intensity is measured as the amount of drug given within a specified period of time [5]. A second measure, known as relative dose intensity is a measure of the amount of drug delivered as a ratio of the amount of drug planned to be administered [6]. By adapting these measures to observational studies of medicine use, dose intensity can be described as the product of the dosage prescribed and the adherence with the dosage prescribed during treatment periods. In general, this should be reported as an average dosage per day. In drug safety research, dose intensity may influence the strength of association with the outcome or adverse drug effect under assessment because the majority of adverse drug effects are dose dependent [7]. Thus, studies involving subjects where the average dose intensity is low may be less likely to show an association than studies where the average dose intensity is high [4].

\subsection{The Influence of Medication Non-Adherence on Outcomes}

There is a significant body of literature showing that there are high levels of non-adherence with medicines in many populations [8-10]. Non-adherence with a medicine can be accidental and minimal, for example, the omission of a single dose, or can range to complete non-adherence, such as when patients do not take any of the prescribed medicine. Within a population, the full spectrum of non-adherence from minimal to full is likely to exist. Hyperadherence is another form of non-adherence, where patients take more than the prescribed dose. The impact of non-adherence with medicines on clinical outcomes may vary by the amount of non-adherence and whether it is predominantly omission or addition of therapy. A metaanalysis of the effect of adherence with any medical treatment on health outcomes demonstrated a $26 \%$ overall risk difference in outcomes between high and low adherence [odds ratio (OR 2.88, $95 \%$ confidence interval (CI) 2.23-3.73] [11]. When limited to studies on medication use, the risk difference was $21 \%$. The analysis showed the effect was more apparent for chronic diseases where the risk difference was $31 \%$; however, a risk difference of $20 \%$ was apparent for acute conditions [11]. For many medicines used for preventive purposes, such as medicines used to treat diabetes, hypertension, and hyperlipidemia, long-term adherence and persistence are factors likely to affect outcomes. However, for other conditions, even small levels of non-adherence, or small interruptions to therapy, can reduce medication effectiveness or cause harms or unintended consequences. Examples include the oral anticoagulants [12, 13], medicines for immunosuppression in transplant recipients [14], oral contraceptives [15], and medicines for treatment of human immunodeficiency virus $[16,17]$.

The majority of pharmacoepidemiological studies assessing adverse drug effects do not report any adherence measures and many neither stratify results by dosage nor report the mean dosages used. We argue that it is time to consider including the need to report measures of dose 
intensity in studies, as well as articulate this requirement in guidelines for reporting pharmacoepidemiological studies. The overall measure should be reported, as should its component parts. Wherever possible, stratification by dose prescribed should be reported; however, in circumstances where this is not appropriate, such as where dose is titrated to a surrogate endpoint, mean dose should be reported. The distribution of adherence scores should be also be reported.

To illustrate the issue, we review the reporting of adherence or dose intensity in the observational studies that have assessed adherence with and safety of the oral anticoagulant dabigatran. We chose an oral anticoagulant as the case study because non-adherence with anticoagulants is associated with increased risk of poor outcomes [18], and there are differences in the dose formulations approved across countries [19]. We compare the outcomes from the observational studies with knowledge generated from the randomized controlled trial that underpinned dabigatran's marketing authorization.

\section{The Dabigatran Example}

\subsection{The Randomized Controlled Trial Evidence for Dabigatran Safety and Efficacy Compared with Warfarin}

Dabigatran is a novel oral anticoagulant that directly inhibits thrombin. The initial randomized controlled trial evidence that supported dabigatran's market authorization was the RE-LY trial, a multi-center, non-inferiority, randomized controlled trial assessing the efficacy and safety of dabigatran in comparison with warfarin [20]. Two different doses of dabigatran were trialed, 110 and $150 \mathrm{mg}$, while warfarin was dose adjusted based on results of prothrombin time. Collectively, the study results demonstrated dabigatran was non-inferior to warfarin at doses of $110 \mathrm{mg}$ [hazard ratio (HR) $0.90,95 \%$ CI 0.74-1.10] and superior to warfarin at doses of $150 \mathrm{mg}$ (HR $0.65,95 \% \mathrm{CI}$ $0.52-0.81$ ) for the primary endpoint of stroke or systemic embolism. With regards to adverse drug effects, major bleeding risk with dabigatran at a dose of $150 \mathrm{mg}$ was similar to that for warfarin (HR 0.93, $95 \%$ CI 0.81-1.07), while there was a lower risk of major bleeding for dabigatran at the $110 \mathrm{mg}$ dose than for warfarin (HR 0.80, $95 \%$ CI 0.69-0.93) [20]. These results are suggestive of a dose-response effect to the adverse drug effect of major bleeding. This dose-response effect was also observed when limiting the analysis of the adverse drug effect to gastrointestinal bleeding. An equivalent risk of gastrointestinal bleeding was observed between dabigatran $110 \mathrm{mg}$ and warfarin (HR 1.10, $95 \%$ CI 0.86-1.41), and a higher risk of gastrointestinal bleeding was observed with dabigatran $150 \mathrm{mg}$ compared with warfarin (HR 1.36, $95 \%$ CI 1.09-1.70) [20].

\subsubsection{The Randomized Controlled Trial Evidence and the Effect of Adherence}

The potential impact that adherence could have on the risk of major bleeding became apparent when the results of the randomized controlled trial were stratified by time in therapeutic range [21]. Time in therapeutic range was measured for the warfarin arm of the trial [21]. A number of factors can influence time in therapeutic range, including adherence, changes in dietary vitamin $\mathrm{K}$ intake, inter-current illness, and co-administration of interacting medicines. The results of the trial were stratified by the quartiles observed in the trial for time in therapeutic range: $<57.1$, 57.1-65.5, 65.5-72.6, and $>76.2 \%$ [21]. For the warfarin patients with time in therapeutic range $>72.6 \%$ (a potential measure of high adherence), the randomized controlled trial results showed that dabigatran $150 \mathrm{mg}$ was non-inferior to warfarin with regards to stroke or systemic embolism (i.e., the superiority disadvantage disappeared) (HR $0.95,95 \%$ CI 0.61-1.48). The reduced risk of major bleeding that had been observed at the 110-mg dose of dabigatran for the collective population was no longer evident compared with the warfarin population that had high periods of time in therapeutic range $(>72.6 \%)$ (HR $0.90,95 \%$ CI 0.67-1.21) [21]. When examining risk of
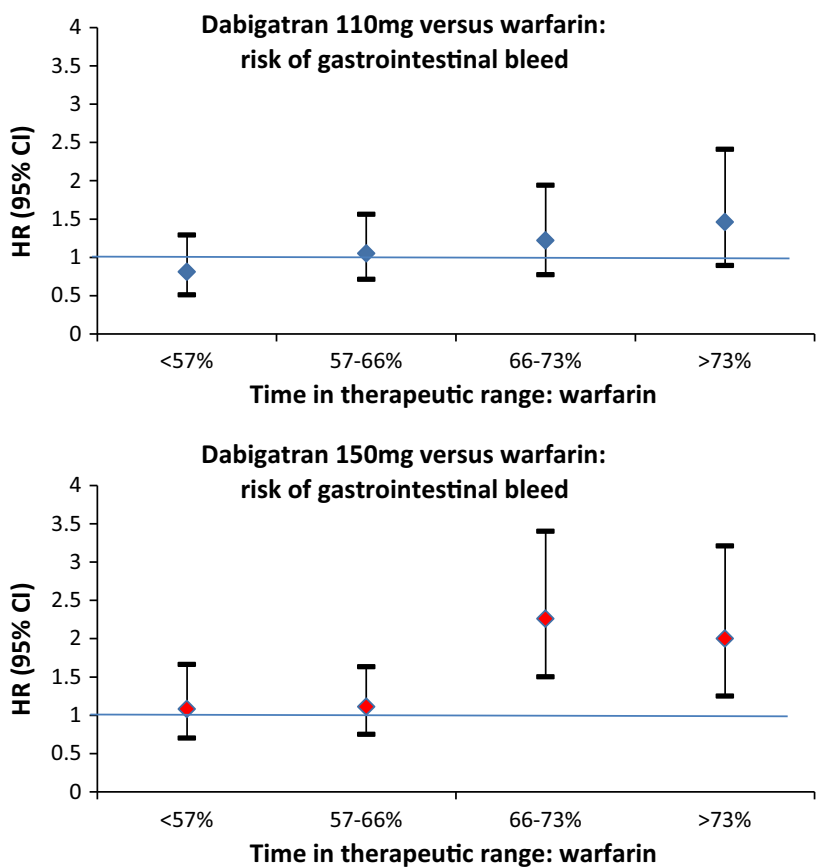

Fig. 1 Risk of gastrointestinal bleed for dabigatran 150 and $110 \mathrm{mg}$ versus warfarin. $C I$ confidence interval, $H R$ hazard ratio (Source: Wallentin et al. 2010) [21] 
gastrointestinal bleeding by time in therapeutic range, the trend in dose response was also apparent (see Fig. 1). One adverse drug effect that remained reduced compared with the warfarin population that had high periods of time in therapeutic range $(>72.6 \%)$ was intracranial bleed, the risk of which was reduced with dabigatran $150 \mathrm{mg}$ compared with warfarin (HR 0.39, $95 \%$ CI 0.18-1.54) [21].

\subsection{Adherence Differences and the Translation of the Trial Results into Practice}

At the time of marketing, concerns were raised about how the RE-LY trial results would translate into practice, as poor adherence to therapy with either dabigatran or warfarin could result in the loss of any therapeutic advantage that one product had over the other [22].

Dabigatran has a dosage schedule of twice daily compared with warfarin's once-daily dosing schedule. Because of the shorter half-life of dabigatran, poor adherence to the twice-daily dabigatran dosage schedule may mitigate any efficacy advantage over warfarin. In addition, a claimed advantage for dabigatran was the lack of a need for monitoring of therapeutic drug levels, a requirement for warfarin that could be a barrier to either initiation or persistence with therapy in some people. However, the requirement for regular monitoring could also provide an opportunity to support adherence to warfarin therapy, and hence the lack of monitoring with dabigatran may result in poorer adherence to dabigatran therapy. Again, if poorer adherence was observed with dabigatran, any efficacy gains would be lost.

Further, the RE-LY trial results demonstrated that the proportion of warfarin patients with time in therapeutic range varied by country, with the mean time in therapeutic range for warfarin as low as $44 \%$ in some countries and up to $77 \%$ in others [21]. Countries where patients on warfarin were in therapeutic range for the majority of time may not realize any therapeutic advantage of dabigatran. Additionally, the trial results demonstrated that patient experience of warfarin use was also a factor in maintaining therapeutic range, with patients naïve to warfarin prior to the study having less time in therapeutic range than patients who had used warfarin previously [21]. Thus, uptake of dabigatran in the warfarin-naïve population compared with the warfarin-experienced population may not yield the same therapeutic advantage.

One additional complicating factor was the response of the USA and European regulators to the trial evidence [19]. Dabigatran was approved at the trial doses of both 110 and $150 \mathrm{mg}$ in Europe; however, in the USA, it was concluded that dabigatran $150 \mathrm{mg}$ was superior to warfarin in all subgroups of patients, thus, the 110-mg dose was not approved [23]. Dabigatran is excreted predominantly via the kidneys, thus, lower dosages are required in patients with renal impairment; for this reason, a dosage of $75 \mathrm{mg}$ was approved in the USA [23]. The 75-mg dose approved in the USA had not been assessed in the clinical trial, thus the clinical efficacy and safety at the 75-mg dose was unknown.

Given the uncertainty about how the clinical trial evidence would translate into practice and the significant potential for patient adherence to influence the results, observational research has focused on assessing adherence to dabigatran or investigating the safety and effectiveness of dabigatran in practice. However, as we highlight in the next section, observational studies of dabigatran's effectiveness and safety do not report adherence levels and do not always report dosages used, all of which have implications for the interpretation of the safety and effectiveness results arising from the observational evidence.

\subsection{The Observational Evidence}

\subsubsection{The Observational Evidence of Adherence with Dabigatran}

We identified three retrospective cohort studies that assessed adherence to dabigatran [24-26]. None of these studies included a warfarin arm. Two of the studies demonstrated high rates of adherence to dabigatran, with more than $70 \%$ of patients considered adherent with therapy $[25,26]$ (Table 1). Consistent with the clinical trial evidence that showed the mean time in therapeutic range for warfarin was as low as $44 \%$ in some countries and varied up to $77 \%$ in others [21], differences in dabigatran adherence rates by site were also evident from the observational evidence [27]. A US study involving 67 sites that had at least 20 patients taking dabigatran reported variation in adherence by site ranging from 42 to $93 \%$ [27]. Median adherence performance by site was $74 \%$. After adjusting for site and patient characteristics, the variation was still found to be present [27].

Two of the observational studies on adherence with dabigatran reported the proportion of the population receiving the $150-\mathrm{mg}$ dose $[25,26]$. The rate was $61 \%$ receiving dabigatran $150 \mathrm{mg}$ in the study from the European country, where both the 110- and the 150-mg doses are available, and higher, at $83.6 \%$ receiving dabigatran $150 \mathrm{mg}$ in the US study, where the 150-mg dosage is recommended for the majority of patients. The higher level of use of dabigatran $150 \mathrm{mg}$ in the USA is consistent with registry data from the USA that found $87 \%$ of dosages of dabigatran were for the 150-mg product [28]. Similarly, the lower level of use of the 150-mg strength in the European study may be reflective of the use of lower doses in countries where the 110-mg strength is available. In 
Table 1 Observational studies assessing adherence with dabigatran

\begin{tabular}{|c|c|c|c|c|c|c|c|}
\hline Study, country & $\begin{array}{l}\text { Study } \\
\text { period }\end{array}$ & Cohort & Measure & $\begin{array}{l}\text { Follow-up } \\
\text { period }\end{array}$ & $\begin{array}{l}\text { Percent } \\
\text { on } \\
150 \mathrm{mg}\end{array}$ & $\begin{array}{l}\text { Mean adherence } \\
\text { score }(\%)( \pm \mathrm{SD})\end{array}$ & $\begin{array}{l}\text { Proportion } \\
\text { adherent (measure } \\
>80 \% \text { ) }\end{array}$ \\
\hline $\begin{array}{l}\text { Gorst-Rasmussen } \\
\text { et al. } 2015 \text { [25], } \\
\text { Denmark }\end{array}$ & $\begin{array}{l}\text { August } \\
\text { 2011- } \\
\text { June 2013 }\end{array}$ & $\begin{array}{l}N=2960 \\
\text { Receiving DAB within } \\
30 \text { days of diagnosis of } \\
\text { AF }\end{array}$ & PDC & 12 months & 61.1 & $83.9( \pm 27.7)$ & $76.8 \%$ \\
\hline $\begin{array}{l}\text { Shore et al. } 2014 \\
\text { [26], USA }\end{array}$ & $\begin{array}{l}\text { Oct } 2010- \\
\text { Sept } 2012\end{array}$ & $\begin{array}{l}N=5376 \\
\text { All pts who filled a DAB } \\
\text { prescription of at least } \\
30 \text { days }\end{array}$ & PDC & 12 months & NR & $84( \pm 22)$ & $\begin{array}{l}72.2 \% \text { (variation } \\
\text { by site } 42-93) \\
{[27]}\end{array}$ \\
\hline $\begin{array}{l}\text { Cutler et al. } 2014 \\
\text { [24], USA }\end{array}$ & $\begin{array}{l}\text { Jan } 2012- \\
\text { Dec } 2012\end{array}$ & $\begin{array}{l}N=159 \\
\text { Pts with AF who filled a } \\
\text { DAB prescription }\end{array}$ & MPR & 12 months & $83.6 \%$ & $63( \pm 35)$ & $57 \%$ \\
\hline
\end{tabular}

$A F$ atrial fibrillation, $D A B$ dabigatran, $M P R$ medication possession ratio, $N R$ not reported, $P D C$ proportion of days covered, pts patients, $S D$ standard deviation

Turkey, only $45 \%$ of dabigatran use was for the higher strength [29], and a European survey reported $61 \%$ of dabigatran use in adults was at the 150-mg strength [30].

\subsubsection{The Observational Evidence of Dabigatran Safety and Effectiveness Compared with Warfarin}

We located five observational studies that had assessed risk of gastrointestinal bleeding with dabigatran compared with warfarin in patients who were naïve to both therapies; two of these also reported outcomes for ischemic stroke [3135]. Uncertainty in the translation of the RE-LY trial to the real-world setting was the rationale underpinning the studies. All of the studies reported outcomes for populations with atrial fibrillation, and these results were extracted for comparison (see Table 2). Four of the studies were based in the USA and one was from Denmark. All studies were retrospective observational studies using electronic health data, and all studies had a new user design. All studies used propensity scores to provide balance across study arms, with two studies using inverse probability of treatment weights (IPTW) and the remaining three studies using matched propensity score designs. All studies provided data to demonstrate how propensity weighting or matching improved covariate balance.

None of the studies reported an average adherence measure or the distribution of adherence scores for participants, despite the observational evidence from separate studies showing between 25 and $40 \%$ could be non-adherent with dabigatran. None of the studies reported time in therapeutic range for subjects receiving warfarin. Only the Danish study stratified results by the dabigatran strength used. None of the US studies reported the proportion of participants receiving the 75-mg dose of dabigatran, nor stratified results by this dose, despite this dose not having been assessed in the clinical trial.

With regards to the outcome of gastrointestinal bleed, two studies reported a significant increased risk of gastrointestinal bleed with dabigatran compared with warfarin, while two studies showed no difference in risk between the two medicines (Table 2). The Danish study, which stratified results by dose, found a lower risk of gastrointestinal bleeding with dabigatran $110 \mathrm{mg}$ than with warfarin and no increased risk with dabigatran $150 \mathrm{mg}$ compared with warfarin (Table 2). With regards to the outcome of ischemic stroke, the Danish study reported no increased effectiveness at dabigatran $150 \mathrm{mg}$ compared with warfarin (HR 1.18, $95 \%$ CI 0.85-1.64) and borderline effectiveness at the 110-mg dose (HR 0.73, $95 \%$ CI 0.53-1) [34]. The mean age of dabigatran users in the Danish study was 67.4 years for the $150-\mathrm{mg}$ dose and 74.7 years for the $110-\mathrm{mg}$ dose. The US study that assessed ischemic stroke found no difference in risk between dabigatran and warfarin users (HR 0.91, $95 \%$ CI 0.81-1.02) [35].

We cannot ascertain the impact of dose intensity, either due to patient non-adherence or due to differential doses prescribed, because these data were not reported in the published studies. However, if there were significant numbers of the population with poor adherence, this would create a bias to the null, and the observational evidence assessing adherence suggests at least a proportion of the population were non-adherent. Similarly, if a significant proportion of the population were receiving the 75-mg dose, this may also create a bias to the null. In the two US studies where increased risk of gastrointestinal bleeding was observed, the dabigatran cohort had higher mean ages than in the US studies where no increased risk was observed (Fig. 2). Given the lack of a 110-mg dose in the 
Table 2 Observational studies assessing gastrointestinal bleeding risk with dabigatran compared with warfarin

\begin{tabular}{|c|c|c|c|c|c|}
\hline Study, country & Study period & Cohort & $\begin{array}{l}\text { Dose intensity } \\
\text { measure }\end{array}$ & $\begin{array}{l}\text { Adherence } \\
\text { measure }\end{array}$ & $\begin{array}{l}\text { GI bleeding } \\
\text { HR }(95 \% \mathrm{CI})\end{array}$ \\
\hline $\begin{array}{l}\text { Chang et al. } 2015 \text { [32], } \\
\text { USA } \\
\text { New user, propensity } \\
\text { weighted }\end{array}$ & $\begin{array}{l}\text { Oct } 2010- \\
\text { Mar } 2012\end{array}$ & $\begin{array}{l}4907 \text { DAB } \\
39607 \text { WAR } \\
\text { Mean age DAB } 62 \text { years }\end{array}$ & NR & NR & $1.21(0.96-1.53)$ \\
\hline $\begin{array}{l}\text { Abraham et al. } 2015 \\
\text { [31], USA } \\
\text { New user, propensity } \\
\text { matched }\end{array}$ & $\begin{array}{r}\text { Nov } 2010- \\
\text { Sep } 2013\end{array}$ & $\begin{array}{l}7749 \text { matched pairs } \\
\text { Mean age DAB } 63.1 \text { years }\end{array}$ & NR & NR & $0.79(0.61-1.03)$ \\
\hline $\begin{array}{l}\text { Lauffenburger et al. } \\
2015 \text { [35], USA } \\
\text { New user, propensity } \\
\text { weighted }\end{array}$ & $\begin{array}{l}\text { Oct } 2010- \\
\text { Dec } 2012\end{array}$ & $\begin{array}{l}21,070 \text { DAB } \\
43,865 \text { WAR } \\
\text { Mean age DAB } 67.5 \text { years }\end{array}$ & NR & NR & $1.11(1.02-1.22)$ \\
\hline $\begin{array}{l}\text { Hernandez et al. } 2015 \\
\text { [33], USA } \\
\text { New user, propensity } \\
\text { weighted }\end{array}$ & $\begin{array}{l}\text { Oct } 2010- \\
\text { Nov } 2011\end{array}$ & $\begin{array}{l}8102 \text { WAR } \\
1302 \text { DAB } \\
\text { Mean age DAB } 75 \text { years }\end{array}$ & NR & NR & $1.85(1.64-2.07)$ \\
\hline $\begin{array}{l}\text { Larsen et al. } 2013 \text { [34], } \\
\text { Denmark }\end{array}$ & $\begin{array}{r}\text { Aug 2009- } \\
\text { Dec } 2012\end{array}$ & $\begin{array}{l}2239 \mathrm{DAB} 150 \mathrm{mg} \text { matched to } 3996 \mathrm{WAR} \\
2739 \mathrm{DAB} 110 \mathrm{mg} \text { matched to } 4940 \mathrm{WAR}\end{array}$ & $\begin{array}{l}\text { Stratified by } 150 \\
\text { and } 110 \mathrm{mg}\end{array}$ & NR & $\begin{array}{l}150 \mathrm{mg}: 1.12 \\
(0.67-1.83)\end{array}$ \\
\hline $\begin{array}{l}\text { New user, propensity } \\
\text { matched }\end{array}$ & & $\begin{array}{l}\text { Mean age: DAB } 150 \mathrm{mg}, 67.4 \text { years; DAB } \\
110 \mathrm{mg}, 74.7 \text { years }\end{array}$ & & & $\begin{array}{r}110 \mathrm{mg}: 0.60 \\
(0.37-0.93)\end{array}$ \\
\hline
\end{tabular}

$C I$ confidence interval, $D A B$ dabigatran, $G I$ gastrointestinal, $H R$ hazard ratio, NR not reported, WAR warfarin

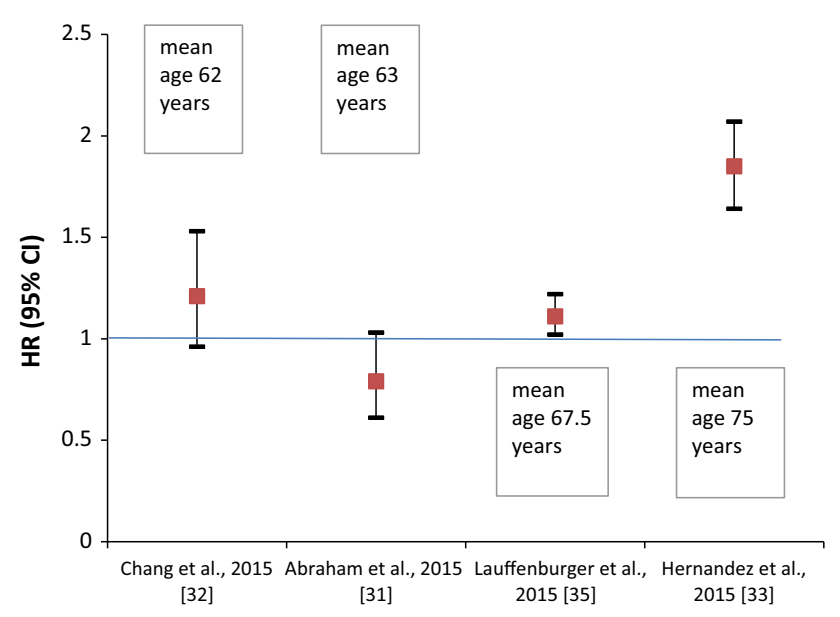

Fig. 2 Risk of gastrointestinal bleeding with dabigatran compared to warfarin users and mean age of study cohort. $C I$ confidence interval, $H R$ hazard ratio

USA and the higher proportion of use of dabigatran $150 \mathrm{mg}$ in the USA than in Europe, it is possible that the differential effect observed in the US studies is partially attributable to a dose-intensity effect. In the USA, $83 \%$ of people aged $\geq 80$ years are prescribed dabigatran $150 \mathrm{mg}$ [28]; in comparison, only $61 \%$ of the elderly in Europe are prescribed the 150-mg dose [34].

\section{The Implications for Medication Safety Research}

In this example, we have shown that despite prior knowledge that the dosage of dabigatran used had a differential effect on both safety and efficacy outcomes, none of the published US studies stratified results by the 75-mg dose, a dose that had not been trialed. Only the Danish study stratified results by dosage used. Further, despite prior concerns that patient adherence would be a factor contributing to whether any potential safety or efficacy gains with dabigatran were realized in practice, none of the studies assessing outcomes reported an adherence measure.

There are potential consequences of not reporting dose intensity with observational studies, particularly as the same strength medicines are not necessarily available in all countries. Meta-analyses of medication safety effects without stratification by dose could be biased by the inclusion of studies where dosages differ substantially across studies [4]. For the dabigatran example, pooling data from all studies would provide a result dominated by the US studies, where a higher dose of dabigatran is routinely used compared with Australia and countries in Europe. This may result in over-estimated risks for countries outside the USA where lower doses are more commonly used. International networks to assess drug safety are developing 
$[36,37]$, and it will be increasingly important to report measures of dose and dose intensity so that valid comparisons within and across countries can be made.

Another example of the limitations of not reporting dose in observational studies is found in the observational studies assessing cardiovascular risk with non-steroidal anti-inflammatory agents. Rofecoxib was approved in the USA in a 50-mg formulation; however, countries such as Australia did not register this dose, only registering the 25 -mg product. At least 34 observational studies have been undertaken assessing cardiovascular risk from rofecoxib; however, the majority have not reported the dose used [38]. Thus, less than half were able to be pooled in analyses to assess dose response. The dose-response analysis revealed a dose-response effect, with a doubling in risk of adverse cardiovascular outcomes [risk ratio (RR) $2.17,95 \%$ CI 1.59-2.97] for doses above $25 \mathrm{mg}$ per day compared with a $37 \%$ increased risk for doses of $25 \mathrm{mg}$ per day or less (RR $1.37,95 \%$ CI 1.20-1.57) [38]. Of the 177 observational studies reported in a meta-analysis assessing cardiovascular risk with non-steroidal anti-inflammatory agents, only onethird were able to be analysed for dose-response effects [38].

\section{Conclusion}

The lack of reporting of dose intensity in observational studies of medication safety is a lost opportunity for improving medication safety research and limits the ability to control for differential doses when undertaking metaanalyses and systematic reviews. This issue could be easily addressed by requirements to include reporting of dose intensity in guidelines for observational study reporting. In a similar way to the requirement to report the results of propensity adjustment on patient characteristics, which all the studies reviewed in this paper did, the guidelines for reporting medication safety studies from electronic health data should include a requirement to report measures of dose intensity and its component parts. Ideally, the measures would include dose stratification or mean dose, where dose stratification is not possible, and a measure of adherence and the distribution of adherence scores across the study population. As guidelines for reporting results of observational studies from electronic health data are developed, we argue that consideration should be given to including a requirement for reporting dose intensity.

\section{Compliance with Ethical Standards}

Funding This work is funded by a National Health and Medical Research Centre (NHMRC) grant; Centre of Research Excellence in post-marketing surveillance of medicines and medical devices GNT
1040938. Nicole Pratt is supported by an NHMRC Early Career Research Fellowship GNT 1035889.

Conflict of interest Elizabeth Roughead and Nicole Pratt have no conflicts of interest to declare.

Open Access This article is distributed under the terms of the Creative Commons Attribution-NonCommercial 4.0 International License (http://creativecommons.org/licenses/by-nc/4.0/), which permits any noncommercial use, distribution, and reproduction in any medium, provided you give appropriate credit to the original author(s) and the source, provide a link to the Creative Commons license, and indicate if changes were made.

\section{References}

1. Center for Drug Evaluation and Research, Center for Biologics Evaluation and Research. Guidance for industry and FDA staff. Best practices for conducting and reporting pharmacoepidemiologic studies using electronic health care data. Rockville: USA Food and Drug Administration; 2013.

2. von Elm E, Altman DG, Egger M, Pocock SJ, Gotzsche PC, Vandenbroucke JP, et al. Strengthening the Reporting of Observational Studies in Epidemiology (STROBE) statement: guidelines for reporting observational studies. BMJ. 2007;335(7624): $806-8$.

3. Nicholls SG, Quach P, von Elm E, Guttmann A, Moher D, Petersen I, et al. The REporting of Studies Conducted Using Observational Routinely-Collected Health Data (RECORD) statement: methods for arriving at consensus and developing reporting guidelines. PloS One. 2015;10(5):e0125620. doi:10. 1371/journal.pone.0125620.

4. Hansen RA, Moore CG, Dusetzina SB, Leinwand BI, Gartlehner $\mathrm{G}$, Gaynes BN. Controlling for drug dose in systematic review and meta-analysis: a case study of the effect of antidepressant dose. Med Decis Making. 2009;29(1):91-103.

5. Longo DL, Duffey PL, DeVita VT Jr, Wesley MN, Hubbard SM, Young RC. The calculation of actual or received dose intensity: a comparison of published methods. J Clin Oncol. 1991;9(11): 2042-51.

6. Yamaguchi H, Hirakawa T, Inokuchi K. Importance of relative dose intensity in chemotherapy for diffuse large B-cell lymphoma. J Clin Exp Hematop. 2011;51(1):1-5.

7. Aronson JK, Ferner RE. Joining the DoTS: new approach to classifying adverse drug reactions. BMJ. 2003;327(7425):1222-5.

8. Sattler EL, Lee JS, Perri M 3rd. Medication (re)fill adherence measures derived from pharmacy claims data in older Americans: a review of the literature. Drugs Aging. 2013;30(6):383-99.

9. Andrade SE, Kahler KH, Frech F, Chan KA. Methods for evaluation of medication adherence and persistence using automated databases. Pharmacoepidemiol Drug Saf. 2006;15(8):565-74 (discussion 75-7).

10. Briesacher BA, Andrade SE, Fouayzi H, Chan KA. Comparison of drug adherence rates among patients with seven different medical conditions. Pharmacotherapy. 2008;28(4):437-43.

11. DiMatteo MR, Giordani PJ, Lepper HS, Croghan TW. Patient adherence and medical treatment outcomes: a meta-analysis. Med Care. 2002;40(9):794-811.

12. Sherwood MW, Douketis JD, Patel MR, Piccini JP, Hellkamp AS, Lokhnygina Y, et al. Outcomes of temporary interruption of rivaroxaban compared with warfarin in patients with nonvalvular atrial fibrillation: results from the rivaroxaban once daily, oral, direct factor Xa inhibition compared with vitamin $\mathrm{K}$ antagonism 
for prevention of stroke and embolism trial in atrial fibrillation (ROCKET AF). Circulation. 2014;129(18):1850-9.

13. Di Minno A, Spadarella G, Tufano A, Prisco D, Di Minno G. Ensuring medication adherence with direct oral anticoagulant drugs: lessons from adherence with vitamin $\mathrm{K}$ antagonists (VKAs). Thromb Res. 2014;133(5):699-704.

14. Shemesh E, Shneider BL, Savitzky JK, Arnott L, Gondolesi GE, Krieger NR, et al. Medication adherence in pediatric and adolescent liver transplant recipients. Pediatrics. 2004;113(4): 825-32.

15. Brynhildsen J. Combined hormonal contraceptives: prescribing patterns, compliance, and benefits versus risks. Ther Adv Drug Saf. 2014;5(5):201-13. doi:10.1177/2042098614548857.

16. Ford N, Irvine C, Shubber Z, Baggaley R, Beanland R, Vitoria M, et al. Adherence to HIV postexposure prophylaxis: a systematic review and meta-analysis. AIDS. 2014;28(18):2721-7.

17. Feelemyer J, Des Jarlais D, Arasteh K, Uuskula A. Adherence to antiretroviral medications among persons who inject drugs in transitional, low and middle income countries: an international systematic review. AIDS Behav. 2015;19(4):575-83.

18. Kneeland PP, Fang MC. Current issues in patient adherence and persistence: focus on anticoagulants for the treatment and prevention of thromboembolism. Patient Prefer Adherence. 2010;4: 51-60.

19. Moore TJ, Cohen MR, Mattison DR. Dabigatran, bleeding, and the regulators. BMJ. 2014;349:g4517.

20. Connolly SJ, Ezekowitz MD, Yusuf S, Eikelboom J, Oldgren J, Parekh A, et al. Dabigatran versus warfarin in patients with atrial fibrillation. New Engl J Med. 2009;361(12):1139-51.

21. Wallentin L, Yusuf S, Ezekowitz MD, Alings M, Flather M, Franzosi MG, et al. Efficacy and safety of dabigatran compared with warfarin at different levels of international normalised ratio control for stroke prevention in atrial fibrillation: an analysis of the RE-LY trial. Lancet. 2010;376(9745):975-83.

22. Sansom L. Review of anticoagulation therapies in atrial fibrillation. Canberra: Australian Government Department of Health and Ageing; 2012.

23. Unger EF. Summary review: Deputy director decisional memo, NDA 22-512 Pradaxa dabigatran etexilate. Silver Spring: USA Food and Drug Administration; 2010.

24. Cutler TW, Chuang A, Huynh TD, Witt RG, Branch J, Pon T, et al. A retrospective descriptive analysis of patient adherence to dabigatran at a large academic medical center. J Manag Care Spec Pharm. 2014;20(10):1028-34.

25. Gorst-Rasmussen A, Skjoth F, Larsen TB, Rasmussen LH, Lip GY, Lane DA. Dabigatran adherence in atrial fibrillation patients during the first year after diagnosis: a nationwide cohort study. J Thromb Haemost. 2015;13(4):495-504.

26. Shore S, Carey EP, Turakhia MP, Jackevicius CA, Cunningham F, Pilote L, et al. Adherence to dabigatran therapy and longitudinal patient outcomes: insights from the veterans health administration. Am Heart J. 2014;167(6):810-7.
27. Shore S, Ho PM, Lambert-Kerzner A, Glorioso TJ, Carey EP, Cunningham $\mathrm{F}$, et al. Site-level variation in and practices associated with dabigatran adherence. JAMA. 2015;313(14):1443-50.

28. Steinberg BA, Holmes DN, Piccini JP, Ansell J, Chang P, Fonarow GC, et al. Early adoption of dabigatran and its dosing in US patients with atrial fibrillation: results from the outcomes registry for better informed treatment of atrial fibrillation. J Am Heart Assoc. 2013;2(6):e000535.

29. Kilickiran Avci B, Vatan B, Tok OO, Aidarova T, Sahinkus S, Uygun $\mathrm{T}$, et al. The trends in utilizing nonvitamin $\mathrm{K}$ antagonist oral anticoagulants in patients with nonvalvular atrial fibrillation: a real-life experience. Clin Appl Thromb Hemost. 2015. doi:10. $1177 / 1076029615581365$

30. Lip GY, Bongiorni MG, Dobreanu D, Lewalter T, Hastrup Svendsen J, Blomstrom-Lundqvist C, et al. Novel oral anticoagulants for stroke prevention in atrial fibrillation: results of the European Heart Rhythm Association survey. Europace. 2013;15(10):1526-32.

31. Abraham NS, Singh S, Alexander GC, Heien H, Haas LR, Crown $\mathrm{W}$, et al. Comparative risk of gastrointestinal bleeding with dabigatran, rivaroxaban, and warfarin: population based cohort study. BMJ. 2015;350:h1857.

32. Chang HY, Zhou M, Tang W, Alexander GC, Singh S. Risk of gastrointestinal bleeding associated with oral anticoagulants: population based retrospective cohort study. BMJ. 2015;350: h1585.

33. Hernandez I, Baik SH, Pinera A, Zhang Y. Risk of bleeding with dabigatran in atrial fibrillation. JAMA Intern Med. 2015;175(1):18-24.

34. Larsen TB, Rasmussen LH, Skjoth F, Due KM, Callreus T, Rosenzweig M, et al. Efficacy and safety of dabigatran etexilate and warfarin in "real-world" patients with atrial fibrillation: a prospective nationwide cohort study. J Am Coll Cardiol. 2013;61(22):2264-73.

35. Lauffenburger JC, Farley JF, Gehi AK, Rhoney DH, Brookhart MA, Fang G. Effectiveness and safety of dabigatran and warfarin in real-world US patients with non-valvular atrial fibrillation: a retrospective cohort study. J Am Heart Assoc. 2015;4(4): e001798.

36. Patadia VK, Coloma P, Schuemie MJ, Herings R, Gini R, Mazzaglia $G$, et al. Using real-world healthcare data for pharmacovigilance signal detection - the experience of the EU-ADR project. Expert Rev Clin Pharmacol. 2015;8(1):95-102.

37. Pratt N, Andersen M, Bergman U, Choi NK, Gerhard T, Huang $\mathrm{C}$, et al. Multi-country rapid adverse drug event assessment: the Asian Pharmacoepidemiology Network (AsPEN) antipsychotic and acute hyperglycaemia study. Pharmacoepidemiol Drug Saf. 2013;22(9):915-24.

38. McGettigan P, Henry D. Cardiovascular risk and inhibition of cyclooxygenase: a systematic review of the observational studies of selective and nonselective inhibitors of cyclooxygenase 2 . JAMA. 2006;296(13):1633-44. 